\title{
Pengelolaan ZIS di LAZ Nurul Hayat Madiun
}

\author{
Faruq Ahmad Futaqi, Anas Saihul Amin, Distyana Dwiyanti, Rinda Wahyu Lestari, Hesti \\ Tri Indah Sari \\ Institut Agama Islam Negeri Ponorogo, Indonesia, \\ futaqi@iainponorogo.ac.id, anassaihulamin27@gmail.com, \\ distyanadwiyanti12@gmail.com, riestari704@gmail.com, hestysamarra@gmail.com
}

\begin{abstract}
:
ZIS management is an important issue in the community empowerment program by the amil zakat institution. This study aims to analyze the management of ZIS at LAZNAS Nurul Hayat. Primarily in ZIS funding and distribution products. The method used in this research is descriptive qualitative. The results of this study describe the management of LAZNAS Nurul Hayat in funding and distributing ZIS. There are 3 ways to funding ZIS, namely: amil picks up zakat from muzaki's house ("picks up the ball"); muzaki transfers zakat, infaq, alms; and muzaki came directly to Nurul Hayat's office. Meanwhile, the distribution of ZIS is carried out through various programs, namely: SAYANG, GENPRES, IBUQU, TAFAQUR, BUNDA YATIM, and SAJADAH. In addition, LAZ Nurul Hayat has Aqiqah Nurul Hayat and BARBEKU business units.
\end{abstract}

Keywords: Zakat, Infaq, Sedekah, Funding, Distributing.

\begin{abstract}
Abstrak
Pengelolaan ZIS merupakan isu penting dalam program pemberdayaan umat oleh lembaga amil zakat. Penelitian ini bertujuan untuk menganalisis pengelolaan ZIS pada LAZNAS Nurul Hayat. Utamanya pada produk penghimpunan dan penyaluran ZIS. Metode yang digunakan dalam penelitian adalah deskriptif kualitatif. Hasil dari penelitian ini menjelaskan tentang pengelolaan LAZNAS Nurul Hayat dalam menghimpun dan mendistribusikan ZIS. Dalam menghimpun ZIS dilakukan dengan 3 cara, yaitu: amil menjemput zakat ke rumah muzaki ("jemput bola"); muzaki mentranfer dana zakat, infak, sedekah; dan muzaki datang langsung ke kantor Nurul Hayat. Sedangkan, penyaluran ZIS dilakukan dengan berbagai program, yaitu: SAYANG, GENPRES, IBUQU, TAFAQUR, BUNDA YATIM, dan SAJADAH. Selain itu LAZ Nurul Hayat memiliki unit usaha Aqiqah Nurul Hayat dan BARBEKU.
\end{abstract}

Kata kunci: Zakat, Infak, Sedekah, Penghimpunan, Penyaluran. 


\section{PENDAHULUAN}

Nurul Hayat merupakan salah satu lembaga sosial yang telah berdiri sejak 2001. Sebagai lembaga sosial, Nurul Hayat melakukan beberapa layanan terkait dengan pemberdayaan umat. Mengutip dari website resmi lembaga disebutkan bahwa Nurul Hayat telah menjadi Lembaga Amil Zakat sejak tahun 2015 berdasarkan SK Menteri Agama RI no 442 tahun 2015 (Nurulhayat.org, n.d.). Melalui surat keputusan tersebut maka Nurul Hayat dapat mengumpulkan dan mengelola dana zakat dari masyarakat. Salah satu program andalan dari Nurul Hayat adalah program pemberdayaan ekonomi dan dhuafa yaitu memberdayakan mustahiq untuk memiliki modal keterampilan dasar sehingga mustahiq diharapkan mampu meningkatkan kualitas dirinya secara optimal.

Pengelolaan ZIS yang baik berkontribusi positip dalam pembangunan nasional. ZIS sebagai salah satu pilar perekonomian islam tidak hanya dipandang sebagai bentuk ritual saja tetapi merupakan instusi yang akan menjamin terciptanya dimensi sosial, ekonomi, keadilan dan kesejahteraan. ZIS juga merupakan instusi yang menjamin adanya distribusi harta dari golongan mampu kepada golongan yang kurang mampu. Dalam perwujudannya ZIS dapat didorong dengan menciptakan lapangan usaha produktif bagi 8 kelompok mustahik. Bentuk dari pengelolaan ini dapat berupa pemberdayaan masyarakat berbasis kelompok yang terus berkelanjutan (Syafaati \& Rani, 2020).

Peran pengelolaan ZIS dapat diwujudkan melalui distribusi harta dari muzaki kepada mustahik untuk mengurangi kesenjangan sosial. Penyaluran ZIS kepada mustahik dilakukan sesuai dengan agenda agar dapat meningkatkan kemampuan mereka dalam mencukupi kebutuhan hidupnya. Pengelolaan ZIS memiliki peran penting dalam mendorong munculnya model terobosan dalam pemberdayaan ekonomi mustahik.

Sebagaimana lembaga Amil Zakat lainnya. Nurul Hayat memiliki program-program pengelolaan dana ZIS. Diantaranya empat bidang program penyaluran, yaitu pendidikan, ekonomi dhuafa, dakwah, dan kesehatan. Pada program bidang pendidikan Nurul Hayat memiliki SMP Tahfidzul Enterpreunership Khoirunnas, pesantren anak sholeh, sahabat yatim cemerlang, sahabat anak soleh, dan kampus enterpreuner. Pada program lainnya Nurul Hayat memiliki program dakwah center Nurul Hayat dan Majelis Ta'lim abang becak. Beberapa program yang dijalankan dalam pemberdayaan ekonomi dhuafa adalah penciptaan lapangan kerja mandiri dan insentif bulanan guru Al Qur'an (Nurulhayat.org, n.d.). Diantara keunikan lain dari LAZ Nurul Hayat adalah biaya operasional dari LAZ tidak mengggunakan dana ZIS. Dana ZIS 100\% disalurkan kepada yang membutuhkan. Mereka berkomitmen bahwa seluruh perolehan dana ZIS distribusikan untuk dakwah dan sosial. Diantara penopang biaya operasional dari LAZ Nurul Hayat adalah usaha Aqiqah dan Barbeku (Barang bekas berkualitas) (Kunaifi, 2020).

Berdasar keunikan ini peneliti tertarik untuk mendalami pengelolaan dana ZIS yang dilakukan oleh LAZ Nurul Hayat. Walapun semua program dari LAZ Nurul Hayat merupakan 
Pengelolaan ZIS di LAZ Nurul Hayat Madiun | Fatuqi. Dkk instruksi dari pusat. Peneliti membatasi penelitian pada pengelolaan ZIS yang dilakukan oleh LAZ Nurul Hayat Madiun. Judul yang diangkat adalah Pengelolaan ZIS di Nurul Hayat Madiun.

\section{TINJAUAN LITERATUR}

\section{Zakat Infak Sedekah}

\section{Pengertian Zakat Infaq Sedekah}

Menurut UU no 23 tahun 2011 Zakat adalah harta yang wajib dikeluarkan oleh seorang muslim atau badan usaha untuk diberikan kepada yang berhak menerimanya sesuai dengan syariat Islam. Zakat dalam islam merupakan kewajiban bagi mereka yang telah memenuhi syarat-syarat. Infak adalah harta yang dikeluarkan oleh seseorang atau badan usaha di luar zakat untuk kemaslahatan umum. Sedangkan, Sedekah adalah harta atau nonharta yang dikeluarkan oleh seseorang atau badan usaha di luar zakat untuk kemaslahatan umum (Undang-Undang, 2011).

Menurut Imam al Mawardi zakat dan sedekah adalah sama. Zakat berarti sedekah dan sedekah berarti zakat. Penyebutannya berbeda tapi hakikatnya sama (Suma, 2015). Namun dalam pengertian di Indonesia zakat berbeda dengan sedekah atau infak. Perbedaan infaq dengan zakat dapat dilihat dari waktu pengeluarannya. Dalam zakat ada nisabnya, infaq dan sedekah tidak ada. Zakat diperuntukkan untuk delapan golongan, sedangkan infaq sedekah dapat diberikan kepada siapapun. Tidak ada ketentuan khusus tentang jumlah kadar dan waktu serah terima.

Sebagaimana yang tertuang di dalam Undang-undang bahwa zakat merupakan pemberian wajib sedangkan infak sedekah adalah pemberian sunah. Zakat menurut bahasa adalah berkembang, bertambah. Zakat kadang diucapkan untuk makna suci atau pujian atau kesalehan. Zakat menurut syariat adalah hak yang wajib pada harta yang harus dikeluarkan dalam jumlah tertentu kepada orang yang berhak menerimanya, telah mencapai nishab, haul (batas waktu mengeluarkan zakat), dan dalam kepemilikan (Zuhaily, n.d.). Adapun syarat-syarat dari zakat adalah sebagai berikut (Zuhaily, n.d.):

1. Merdeka, yang dimaksud merdeka adalah seseorang tersebut tidak dalam kondisi menjadi budak.

2. Islam. Zakat hanya wajib bagi orang Islam karena tujuan dari zakat adalah ibadah untuk menyucikan harta. Ibadah ini tidak berlaku bagi orang non muslim.

3. Baligh dan berakal. Tidak ada kewajiban zakat atas anak kecil dan orang gila menurut hanafiah. Namun, mayoritas ulama tidak mensyaratkan Baligh dan berakal. Para ulama tetap mewajibkan zakat yang ditanggung oleh walinya.

4. Kondisi Harta yang wajib dizakati. Diantaranya adalah uang kertas, barang tambang, barang temuan, barang dagangan, tanaman, buah-buahan, binatang ternak yang dilepas menurut mayoritas ulama. Kondisi harta ini juga disyaratkan berkembang. Karena zakat tidak terjadi kecuali pada harta yang berkembang. 
5. Kondisi harta sampai dengan satu nishab. Satu nishab adalah sebagi tanda bahwa harta tersebut telah wajib dizakati. Emas 20 dinar, perak 200 dirham, biji-bijian dan buah-buahan setelah kering $563 \mathrm{~kg}$. Nishab pertama untuk hewan kambing 40 ekor, unta 5 ekor, sapi 30 ekor.

6. Kepemilikan yang sempurna terhadap harta. Menurut Maliki kepemilikan sempurna adalah kepemilikan asli dan kemampuan untuk mengelola apa yang dimiliki.

7. Haul, Haul adalah berlalu satu tahun atau genap satu tahun qomariyah kepemilikan satu nishab. Genap satu tahun penuh adalah syarat untuk zakat selain tanaman dan buah-buahan.

Dalil Hukum Zakat Infak Sedekah

Zakat merupakan kewajiban bagi orang muslim yang telah memenuhi syarat-syarat wajib zakat. Dasar hukum zakat terdapat di dalam ayat-ayat al quran. Diantaranya dalam surat al baqarah ayat 43 dan 277 :

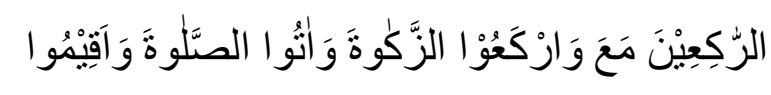

Artinya:

"Dan laksanakanlah sholat, tunaikanlah zakat, dan rukuklah beserta orang yang rukuk" (Q.S. Al Baqarah 43)

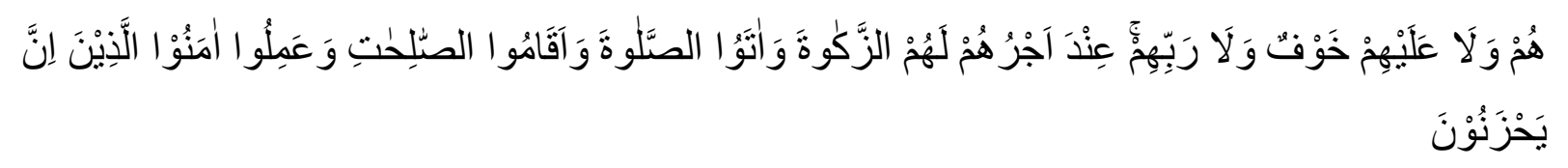

Artinya:

"Sungguh, orang-orang yang beriman, mengerjakan kebajikan, melaksanakan salat dan menunaikan zakat, mereka mendapat pahala di sisi Tuhannya. Tidak ada rasa takut pada mereka dan mereka tidak bersedih hati." (Q.S. Al Baqarah 277)

Sedangkan ayat tentang sedekah tertuang dalam Q.S an Nisa Ayat 114:

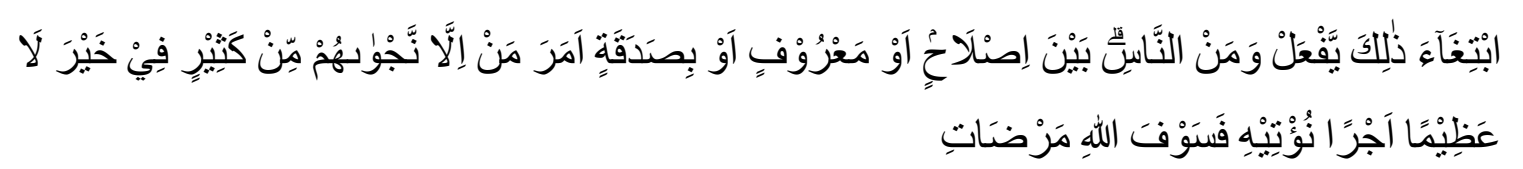

“Tidak ada kebaikan dari banyak pembicaraan rahasia mereka, kecuali pembicaraan rahasia dari orang yang menyuruh (orang) bersedekah, atau berbuat kebaikan, atau mengadakan perdamaian di antara manusia. Barangsiapa berbuat demikian karena mencari keridaan Allah, maka kelak Kami akan memberinya pahala yang besar.” (Q.S. An Nisa: 114)

Ayat tentang Infak tertuang dalam surat Al Baqarah ayat 245:

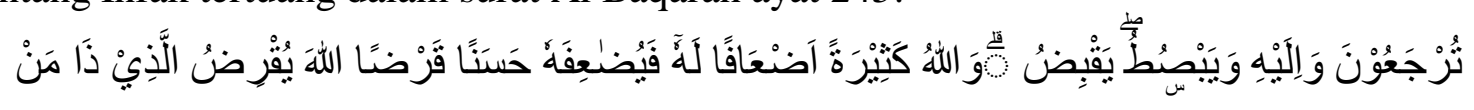




\section{Hikmah Zakat Infak Sedekah}

Menurut Wahbah Zuhayli berikut merupakan hikmah dari zakat (Zuhaily, n.d.):

1. Menjaga dan melindungi harta dari penglihatan orang yang tidak suka, pelaku kejahatan dan jangkauan orang-orang yang berdosa.

2. Zakat membantu para golongan fakir miskin untuk mencukupi kebutuhannya.

3. Menyucikan dari berbagai sifat kikir dan bakhil serta menumbuhkan sifat kedermawanan yang tidak hanya sebatas zakat yang dikeluarkan.

4. Mensyukuri terhadap nikmat harta yang diperolehnya.

\section{Lembaga Amil Zakat}

Berdasarkan Keputusan Menteri Agama RI Nomor 581 tahun 1999 dinyatakan bahwa Lembaga Amil Zakat (LAZ) harus memiliki persyaratan profesional dan transparansi. Hal ini sebagai wujud tanggung jawab dalam pengelolaan dana umat yang dimanahkan kepadanya. Diantara syarat-syarat yang harus dipenuhi oleh Lembaga Amil Zakat adalah berbadan hukum, memiliki tata buku administrasi yang rapi, mempunyai data muzzaki dan mustahik yang baik, memiliki rangkaian program-program kerja yang jelas, dan melampirkan kesediaan surat penyataan siap diaudit (Hafidhuddin, 2002)

Sesuai dengan amanah Undang-undang No. 38 Tahun 1999 tentang pengelolaan zakat diwajibkan untuk membentuk Badan Amil Zakat (BAZ) bagi pemerintah dan Lembaga Amil Zakat (LAZ) bagi masyarakat. BAZ dan LAZ yang terbentuk diharapkan mampu untuk mengelola zakat infak dan shodaqah secara terpusat dan dikelola secara profesional. ZIS dapat dikelola dan tersalurkan dengan tepat dan optimal (Soemitra, 2015, p. 50). Secara struktur organisasi menurut hafidudin BAZ atau LAZ terdiri dari Dewan Pertimbangan, Komisi Pengawasan, dan Badan Pelaksana harian (Hafidhuddin, 2002).

Penanganan kesejahteraan masyarakat miskin merupakan tanggung jawab kita bersama. Utamanya pemerintah. Upaya untuk menanggulangi kemiskinan dan pemerataan kesejahteraan rakyat dilakukan salah satunya melalui pengelolaan zakat, infak, dan shadaqah yang profesional. Pengelolaan ZIS dengan berbagai inovasinya merupakan solusi dan sangat membantu dalam mengatasi kemiskinan yang hari demi hari terus mengalami peningkatan. (Hudaifah et al., 2020, p. 2). Maka, dalam mengelola ZIS dibutuhkan amil yang profesional, fokus dan serius dalam pendayagunaannya.

\section{Pengelolaan ZIS}

Menurut Undang-Undang yang dimaksud Pengelolaan Zakat adalah kegiatan perencanaan, pelaksanaan, dan pengoordinasian dalam pengumpulan, pendistribusian, dan 

pendayaagunaan zakat. Tujuan dari pengelolaan Zakat adalah meningkatkan efektifitas dan efisiensi serta manfaat zakat untuk mewujudkan kesejahteraan masyarakat dan penanggulangan kemiskinan. Lebih lanjut, menurut undang-undang pengelolaan Zakat harus berlandaskan: syariat Islam, amanah, kemanfaatan, keadilan, kepastian hukum, terintgrasi, dan akuntabilitas. (Undang-Undang, 2011)

\section{Telaah Pustaka}

Dalam penelitian ini ditampilkan penelitian terdahulu yang telah dilakukan terkait dengan pengelolaan ZIS diantaranya:

Pertama, penelitian yang dilakukan oleh Muhammad Amin Suma yang berjudul Zakat, Infak, dan Sedekah: Modal dan Model Ideal Pembangunan Ekonomi dan Keuangan Modern. Tujuan dari penelitian ini adalah memaknai zakat infak dan sedekah dalam kontribusi modal untuk pembangunan ekonomi dan keuangan modern. Hasil dari penelitian ini menunjukkan bahwa potensi zakat di Indonesia senilai 217 trilyun mampu untuk membangkitkan ekonomi nasional. Hal ini perlu sinergi antara lembaga amil zakat dan pemerintah untuk merealisasikannya (Suma, 2015).

Kedua, penelitian yang dilakukan oleh Muklisin yang berjudul Strategi Pengelolaan Zakat dalam Upaya Mengembangkan Usaha Produktif (Studi Kasus BAZNAS Kabupaten Bungo). Tujuan dari penelitian ini adalah menganalisi strategi yang dilakukan oleh Baznas Kabupaten Bungo dalam pengelolaan Zakat Infak dan Sedekah. Hasil dari penelitian ini menunjukkan bahwa pengelolaan dan pengembangan zakat di Baznas Bungo menggunakan strategi Pengenalan masalah, Penciptaan peluang usaha, mengembangkan usaha produktif, membuat jaringan usaha, dan memanfaatkan peran Bappeda (Muklisin, 2018).

Ketiga, penelitian yang dilakukan oleh Fauzul Mizanul Ahsan dan Raditya Sukmana yang berjudul Analisis Pengumpulan dan Pengelolaan Zakat, Infak dan Shodaqoh di Lazis Muhammadiyah Lamongan. Tujuan dari penelitian ini adalah menganalisis pengelolaan dari penghimpunan dan penyaluran ZIS di Lazismu Lamongan. Hasil dari penelitian ini menunjukkan bahwa pengelolaan ZIS di Lazismu Lamongan menggunakan prinsip POAC (Planing, Organizing, Actuating dan Controling). Sedangkan dalam penyalurannya memperhartikan 8 golongan yang telah digariskan oleh syariat. (Ahsan \& Sukmana, 2020)

Keempat, penelitian yang dilakukan oleh Ahmad Thoharul Anwar yang berjudul Zakat Produktif untuk Pemberdayaan Ekonomi Umat. Tujuan penelitian ini adalah menganalisis mekanisme penyaluran zakat produktif yang dilakukan oleh Lazisnu Kudus. Hasil dari penelitian ini menunjukkan bahwa Lazisnu Kudus menggunakan mekasnisme yang ketat untuk penyaluran zakat produktif dimana mereka menggunakan kerangka 8 asnaf. Adapun langkahlagkah yang digunakan adalah pendataan, pembinaan, pendampingan, dan pengawasan. (Thoharul Anwar, 2018)

Kelima, penelitian yang dilakukan oleh Muhammad Azis yang berjudul Strategi Pengelolaan Zakat Secara Produktif pada Amil Zakat dalam Tinjauan UU RI Nomor 23 Tahun 
2011 Tentang pengelolaan Zakat (Studi Kasus di Nurul Hayat Kantor Cabang Tuban Periode 2015 - 2016). Tujuan dari penelitian ini adalah menganalisis implementasi Undang-Undang Pengelolaan zakat pada LAZ Nurul Hayat Surabaya. Hasil dari penelitian ini adalah pengelolaan zakat secara produktif di Lembaga Amil Zakat Nurul Hayat Cabang dengen pengadaan program: Pilar Mandiri, Beasiswa Pendidikan, dan Pendirian Pendidikan Formal Unggulan. (Aziz, 2017)

\section{RESEARCH METHOD (METODE PENELITIAN)}

Penelitian ini merupakan penelitian deskriptif kualitatif bersifat studi kasus. Obyek sekaligus Lokasi penelitian adalah di Lembaga Amil Zakat Nasional (LAZNAS) Nurul Hayat Madiun Jl. Kapten Tendean No. 28 A, Sogaten, Sidorejo, Wungu, Kota Madiun, Jawa Timur 63181. Adapun jenis data yang digunakan yaitu data sekunder yang diperoleh dengan cara dokumentasi dan data primer diperoleh dengan cara wawancara serta observasi langsung di lapangan. Metode pengumpulan data yang digunakan dalam penelitian ini yaitu peniliti terlibat langsung dalam kegiatan LAZNAS Nurul Hayat untuk melakukan dokumentasi dan wawancara. Wawancara dilakukan dengan personil LAZNAS Nurul Hayat yaitu Khoirur Rohman Branch Manajer dan Afif Kunaifi Manajer Program Nurul Hayat Madiun serta karyawan Nurul Hayat Madiun.

\section{HASIL DAN PEMBAHASAN}

Profil LAZ Nurul Hayat

LAZ Nurul Hayat berdiri pada tahun 2001 berawal dari sebuah panti asuhan. Merupakan hasil usaha dari H. Muhammad Molik (pengusaha madu) yang menyisihkan sebagian rezekinya untuk anak yatim. Badan Hukum Panti Asuhan Nurul Hayat berdasar SK. Menteri Kehakiman RI tanggal 21 September 1999 No C-1805. HT.03.02 - Th. 1999. Perkembangan selanjutnya Panti Asuhan Nurul Hayat membentuk Yayasan dengan SK. Menteri Hukum \& HAM RI Nomor C-3242. HT.01.02 - Th. 2007. Selanjutnya LAZ Nurul Hayat semakin tumbuh besar dengan berbagai cabang di Indonesia. Pada akhirnya tahun 2015 mendapatkan izin menjadi Lembaga Amil Zakat Nasional dengan SK. Menteri Agama Nomor 244 tahun 2015. Sampai dengan saat ini LAZ Nurul Hayat telah memiliki lebih dari 30 cabang di Indonesia. Visi dari LAZ Nurul Hayat adalah mengabdi kepada Allah dengan membangun umat. Sedangkan misi dari Nurul Hayat adalah Menebar Kemanfaatan dan Pemberdayaan di Bidang Sosial, Dakwah, Kesehatan, Pendidikan dan Ekonomi. Sedangkan tagline dari Nurul Hayat adalah Amanah, Profesional dan Sejuk Semua (Nurulhayat.org, n.d.).

Penghimpunan Dana dan Program Penyaluran LAZ Nurul Hayat

Salah satu pengelolaan zakat sebagaimana diamanahkan oleh Undang-undang adalah perencanaan dan pelaksanaan pengumpulan dana sebagaimana termaktub dalam pasal 7 UU no 
Dalam penghimpunan dana mereka menggunakan 3 cara:

1. Tim FR (Fundrising)

Tim FR adalah tim yang dibentuk oleh Nurul Hayat untuk menjemput donasi langsung kepada donatur. Setiap bulan Tim FR rutin mengambil donasi ke rumah-rumah donator tetap. Sebelumnya tim fundraising menghubungi kontak para donatur tetap untuk melakukan penjemputan donasi.

Jika sudah bertemu dengan donatur maka tim fundraiser mengambil dana ZIS sesuai dengan kesepakatan pada saat awal pendaftaran, lalu donatur diberi slip sebagai bukti mereka berdonasi. Slip ini berfungsi agar transparansi dalam bertransaksi dan menjaga data penginputan.

2. Via transfer ke rekening Lembaga (TF)

Mekanisme transfer dilakukan oleh Nurul Hayat manakala muzaki atau donatur tidak sempat menyetor uangnya langsung ke Tim FR. Para donatur dapat langsung mendonasikan uangnya melalui rekening lembaga Nurul Hayat. Selain itu donatur yang tidak bisa terjangkau lokasinya dari Nurul Hayat karena jarak tempuh yang sangat jauh maka donatur dapat memilih opsi via transfer.

Via transfer bertujuan agar donatur mudah, praktis, dan cepat dalam menyalurkan ZIS. Donatur dapat mentranfer melalui bank mandiri, BCA, dan BNI Syariah. Setelah melakukan transfer, donatur melakukan konfirmasi kepada amil dengan foto bukti transfer. Kemudian Nurul Hayat akan memberikan gift berupa majalah yang setiap bulannya berganti edisi. Majalah-majalah tersebut dapat dikirim rutin melalui via pos.

3. Datang langsung ke kantor Nurul Hayat.

Muzaki atau donatur langsung datang ke kantor Nurul Hayat untuk melakukan donasi langsung. Hal ini biasanya dilakukan oleh para donatur yang dekat dengan kantor Nurul Hayat. Di kantor, donatur disambut oleh karyawan bagian front office yang bertugas melayani donatur dan mengarahkan donatur dengan ramah. (Rohman, 2020)

Menurut penuturan Saifur Rohman, Branch Manager Nurul Hayat Madiun untuk menggaet supaya donatur tumbuh membesar mereka membentuk tim Zakat Advisor (ZA) dengan berbagai program-program (Rohman, 2020). Tugas utama dari tim ZA adalah mencari donatur sebanyak-banyaknya dengan cara menawarkan program-program penyaluran ZIS yang dilakukan oleh Nurul Hayat kepada masyarakat. Diantara program-program yang ditawarkan oleh tim ZA Nurul Hayat kepada masyarakat adalah sebagai berikut:

1. SAYANG

SAYANG adalah singkatan dari Santunan Yatim Cemerlang. Program ini berisi santunan kepada anak yatim yang memiliki kelebihan prestasi mulai dari anak SD sampai SMA. pemberian tersebut berupa uang dan sesuai dengan tingkat sekolahnya. Santunan untuk anak SD senilai Rp. 250.000, sedangkan tingkat SMP sampai dengan SMA senilai Rp. 350.000. Pemberian ini dimaksudkan untuk membantu mereka yang tidak mampu untuk 

menggapi cita-citanya sebagaimana orang mampu lainnya. Selain itu, santunan juga diberikan setiap semester berupa peralatan sekolah setiap semester sebanyak 6.842 kepada anak yatim.

\section{GENPRES}

GEPRES atau Generasi Prestasi adalah program nurul hayat yang memberikan bantuan kepada anak yang berprestasi. Meliputi sahabat muda, sekolah anak sholeh, program bantuan al-Qur'an untuk penyandang tunanetra serta pengadaan gedung pesantren tahfidz al-Qur'an. Pembagian bantuan tersebut mulai dari pendidikan agama hingga bekal skill yang menunjang siswa-siswi. Saat ini jumlah anggota GENPRES sebanyak 250 siswa dari eks Karesidenan Madiun.

\section{IBUQU}

IBUQU atau disebut juga Insentif Bulanan Guru Qur'an. Program pemberian insentif mengajar qur'an saat ini mencapai 5.364 guru. Program tersebut, ada pada setiap 1 bulan sekali dengan memberikan uang jasa kepada ustadz dan ustadzah yang sedang mengajar di TPQ/TPA sewilayah karisidenan madiun.

\section{TAFAQUR}

TAFAQUR adalah Tanda Cinta Untuk Penghafal Al-Qur'an. Bantuan ini berupa uang tunai bulanan kepada para penghafal qur'an yang berkomitmen untuk menjaga hafalannya. Diantara kriteria penerima bantuan TAFAQUR ini adalah:

1. Orang-orang yang menghafal al-Quran 30 juz dan kondisinya lemah

2. Berupa beasiswa pendidikan kepada pelajar atau mahasiswa yang memiliki komitmen untuk menghafal al-qur'an 30 juz. Beasiswa diberikan dengan prasyarat mereka harus hafal minimal 30 juz. Selanjutnya setiap dua bulan mereka harus menjaga/menambah hafalan mereka.

3. Santri yatim di pesantren tahfidz.

\section{BUNDA YATIM}

Program ini diwujudkan dengan diadakannya pelatihan, pemberdayaan ekonomi kepada para bunda anak-anak yatim. Program Bunda Yatim bertujuan agar mereka lebih tenang dalam memberikan pendidikan islami kepada buah hatinya.

6. SAJADAH

SAJADAH adalah Santunan Janda Dhuafa berupa pemberian sembako kepada orang janda yang dhuafa. Tujuan dari pemberian ini untuk membantu orang janda dan orang kurang mampu dari segi materi dan non materi. Selain sembako pihak Nurul Hayat juga memberikan bantuan berupa konribusi material untuk pembangunan rumah.

\section{SAHABAT}

SAHABAT adalah singkatan dari Santunan Hadiah Untuk Berobat. Santunan ini diberikan kepada orang yang sedang mengalami sakit dan kurang mampu berupa pengobatan gratis.

Saat ini kurang lebih 1000 orang dhuafa yang yang telah mendapatkan program ini. 

Selain program-program diatas Nurul Hayat juga memiliki program lain diantaranya layanan ambulan gratis untuk dhuafa, sumber air bersih untuk warga desa yang kesulitan air, dan sigap (aksi tanggap bencana). Nurul Hayat juga mengadakan Program Penanaman 10.000 pohon di Pacitan bekerja sama dengan pemuda setempat dan Mahasiswa MAZAWA'18 IAIN Ponorogo dengan tema "Pemuda Untuk Pacitan". Hal ini sekaligus untuk mempromosikan LAZ Nurul Hayat.

Program Pemberdayaan Nurul Hayat Madiun (Kunaifi, 2020)

Secara khusus Nurul Hayat Madiun melakukan program Pemberdayaan Ekonomi dan Dhuafa dengan Ternak Desa Berdaya yaitu pemberdayaan petani dan peternak. Nurul Hayat mendistribusikan dana sebesar Rp. 100.000.000 untuk pemberdayaan ternak, dan dari dana tersebut dibelikan domba bakalan per orang 10 ekor. Program ini diharapkan mampu meningkatkan ekonomi kaum dhuafa.

Selain program ternak, Nurul Hayat memiliki program warung berkah. Warung berkah merupakan program setiap hari jumat yang menggratiskan masyarakat dhuafa yang makan di warung tersebut. Pemilik warung berkah binaan Nurul Hayat bernama Mbah Salma. Setiap jumat Mbah Salma menggratiskan makanannya dan setelah itu dia melaporkan berpa porsi yang telah terjual pada hari itu. Lalu, Nurul Hayat membayarnya. Program ini sangat disenangi oleh Mbah Salma karena mampu menambah modal usahanya dan dagangannya laris terjual.

Dalam melakukan program pemberdayaan ini menurut Afif Kunaifi Manajer Program Nurul Hayat ada beberapa hal yang dilakukan:

1. Pemantauan

Pemantauan ini bertujuan untuk sebagai bahan informasi bagi Nurul Hayat untuk mengetahui sejauh mana perkembangan usaha mustahik. Selain itu untuk mengetahui apakah dana bantua dapat dimanfaatkan dengan baik oleh mustahik. Pemantuan juga termasuk masalah ibadah. Apakah ibadah shalatnya rajin atau semakin rajin setelah diberi bantuan.

2. Pembimbingan

Pembimbingan disini adalah adanya arahan untuk mustahik agar melakukan usahanya dengan baik. Apabila mustahik mengalami kesulitan dalam usahanya maka Nurul Hayat akan memberikan solusi untuk bisa membangun usahanya dengan lebih baik.

3. Motivasi

Motivasi adalah suatu dorongan untuk lebih baik yang dilakukan oleh Nurul Hayat sebagai wujud mencapai visi dan misi program dari Nurul Hayat. Motivasi ini bertujuan untuk menambah semangat dari dalam diri mustahik untuk tetap bersemangat apabila ada kendala dalam usahanya.

4. Evaluasi

Setelah adanya implementasi maka adanya evaluasi. Evaluasi menjadi bahan pertimbangan Nurul Hayat untuk melihat apakah mustahik yang diberi bantuan ekonominya meningkat 

atau belum. Selain itu evaluasi berguna sebagai bahan pertimbangan dan masukan Nurul Hayat untuk kedepannya. Seperti Mbah Salma, penerima bantuan program warung berkah yang kini berhasil menjadi mustahik yang mandiri.

\section{Program Usaha Nurul Hayat}

Salah satu hal yang menarik dari Nurul hayat adalah komitmen yang terus dipegangnya yaitu biaya operasional tidak mengambil dari dana zakat, infak, dan sedekah namun dipenuhi dengan hasil usaha, sehingga ZIS $100 \%$ tersalurkan untuk mendukung layanan sosial dan dakwah. Hal ini membedakan dengan lembaga amil zakat lainnya. Komitmen ini diwujudkan oleh LAZ Nurul Hayat dengan beberapa unit usaha yang telah dibangun, yaitu:

\section{Usaha Aqiqah Nurul Hayat}

Usaha aqiqah Nurul Hayat didirikan untuk melayani masyarakat yang membutuhkan hajat aqiqah. Semua keperluan masakan aqiqah disediakan oleh Nurul Hayat, masyarakat cukup membayar harganya. Ada beberapa tipe aqiqah yang dijual oleh Nurul Hayat. Mulai tipe menu sedang sampai dengan tipe menu mahal. Pembeli cukup memesan terlebih dahulu dan memberikan uang muka, maka pesanan akan disajikan sesuai permintaan pembeli. Menu yang disajikan adalah sate dan gule kambing atau menu lainnya sesuai selera dari pembeli. Kulit dan kepala kambing ditawarkan kepada pembeli untuk diinfakkan atau dimasak. Jika pembeli ingin dimasak, maka ada biaya tambahan. Jika diinfakkan ke Nurul Hayat maka akan disalurkan untuk program-program sosial Nurul Hayat. Beberapa orang yang berperan dalam memasak menu aqiqah di Nurul Hayat Madiun adalah Bu Titik, Pak Minto dan Bu Wiwik. Mereka adalah juru masak Nurul Hayat. Sedangkan masakan yang sudah jadi diantar ke pembeli oleh Pak Minto.

Dalam memperluas jaringan usaha aqiqah ini, Nurul Hayat juga membuka selebarlebarnya masyarakat untuk menjadi mitra. Masyarakat yang berminat diajari mulai dari promosi sampai dengan manajemen dan cara memasaknya. Selanjutnya Nurul Hayat berbagi hasil atas setiap penjualan yang terjadi.

\section{Usaha BARBEKU (Barang Bekas Berkualitas)}

Barbeku (barang bekas berkulitas) merupakan salah satu program yang dikembangkan oleh Nurul Hayat Madiun. Dimana penghimpunannya melalui penjemputan ke rumah muzaki yang akan menyumbangkan barbeku. Contoh barbeku yang dihimpun yaitu handphone bekas, kulkas bekas dan barang-barang bekas lainnya. Barang-barang bekas tersebut selanjutnya akan dimanfaatkan kembali atau dijual kepada orang lain. Barang apapun yang tidak berguna bagi muzaki dan dirasa masih memberi manfaat dapat dimasukkan dalam program Barbeku. Barang bekas berkualitas tersebut dapat dibenahi terlebih dahulu supaya berfungsi menjadi lebih bernilai, berkah dan tentunya bermanfaat untuk dakwah dan kemaslahatan umat Islam. 


\section{KESIMPULAN}

Dalam pengelolaannya LAZNAS Nurul Hayat telah melakukan beberapa program baik dalam hal penghimpunan maupun penyaluran ZIS. LAZNAS Nurul Hayat juga memiliki unit usaha yang menopang operasionalnya. Penghimpunan dilakukan dengan cara mempermudah muzaki untuk berdonasi: dikunjungi, transfer atau setor mandiri ke kantor LAZ Nurul Hayat. Muzaki juga diberikan laporan berkala sebagai wujud tanggung jawab. Program Penghimpunan dilakukan dengan cara menawarkan program penyaluran yang dilakukan oleh LAZ Nurul Hayat. Program tersebut adalah SAYANG, GENPRES, IBUQU, TAFAQUR, BUNDA YATIM, dan SAJADAH serta program-program insidental dan kreatif lainnya. Selain itu LAZ Nurul Hayat memiliki unit usaha Aqiqah Nurul Hayat dan BARBEKU (Barang Bekas Berkualitas). LAZNAS Nurul Hayat cukup baik dan profesional dalam pengelolaan penghimpunan dan penyaluran ZIS.

\section{REFERENSI}

Ahsan, F. M., \& Sukmana, R. (2020). Pengumpulan Dan Pengelolaan Zakat, Infaq Dan Shodaqoh (Lazis Muhammadiyah Lamongan). Jurnal Ekonomi Syariah Teori Dan Terapan, 6(12), 2393. https://doi.org/10.20473/vol6iss201912pp2393-2408

alqur'an. (2009). al qur'an dan terjemahan. Pustaka Alfatih.

Aziz, M. (2017). Strategies for Productive Zakat Management at Amil Zakat Institutions in the Review of Law of the Republic of Indonesia Number 23 of 2011 concerning Zakat Management (Case Study at Nurul Hayat Tuban Branch Office 2015-2016). AL HIKMAH: Journal of Islamic Studies, 7(1), 1-27.

Hafidhuddin, D. (2002). Zakat dalam Perekonomian Modern. Gema Insani.

Hudaifah, A., Tutuko, B., Abdurrubi P, S., Ishaq, A. A., \& Albar, M. (2020). Sinergi Pengelolaan Zakat di Indonesia. Scopindo Media Pustaka.

Kunaifi, A. (2020). wawancara.

Muklisin, M. (2018). STRATEGI PENGELOLAAN ZAKAT DALAM UPAYA PENGEMBANGKAN USAHA PRODUKTIF (Studi Kasus Pada BAZNAS Kabupaten Bungo). JURIS (Jurnal Ilmiah Syariah), 17(2), 205. https://doi.org/10.31958/juris.v17i2.1174

Nurulhayat.org. (n.d.). No Title.

Rohman, K. (2020). wawancara.

Soemitra, A. (2015). Bank \& Lembaga Keuangan Syariah. Prenada Media.

Suma, M. A. (2015). Zakat, Infak, dan Sedekah: Modal dan Model Ideal Pembangunan Ekonomi dan Keuangan Modern. Al-Iqtishad: Journal of Islamic Economics, 5(2). https://doi.org/10.15408/aiq.v5i2.2568

Syafaati, N. D., \& Rani, L. N. (2020). Pendayagunaan Zakat, Infaq, Dan Shadaqah Baznas Gresik Dalam Pemberdayaan Ekonomi Masyarakat Desa Babaksari Melalui Program Gresik. Jurnal Ekonomi Syariah Teori Dan Terapan, 7(12), 2296. https://doi.org/10.20473/vol7iss202012pp2296-2312

Thoharul Anwar, A. (2018). Zakat Produktif Untuk Pemberdayaan Ekonomi Umat. ZISWAF : Jurnal Zakat Dan Wakaf, 5(1), 41. https://doi.org/10.21043/ziswaf.v5i1.3508

Undang-Undang. (2011). Pengelolaan Zakat UU No. 23 TH. 2011 (p. t.h.).

Zuhaily, W. (n.d.). Fiqih Islam Wa Adillatuhu Jilid 3. Gema Insani Pers. 